\title{
Synchronous Orofacial Granulomatosis in a Patient with Brain Cavernous Hemangioma
}

\author{
Seung Ju Yun, Ji Young Lee, Gwang Hoon Kim, Jong Heon Jeong, Ai-Young Lee, Seung Ho Lee, \\ Jong Soo Hong
}

Department of Dermatology, Dongguk University Ilsan Hospital, Dongguk University College of Medicine, Goyang, Korea

\begin{abstract}
Orofacial granulomatosis is a rare granulomatous inflammatory disease, characterized by recurrent orofacial swelling. Infectious, genetic, and immunologic etiologies are suggested, but not fully understood. Herein, we report a case of synchronous orofacial granulomatosis with brain cavernous hemangioma in a 44-year-old female patient, which may be considered paraneoplastic syndrome. (Ann Dermatol 31(6) $678 \sim 680,2019$ )
\end{abstract}

\section{-Keywords-}

Cavernous hemangioma, Orofacial granulomatosis, Paraneoplastic syndrome

\section{INTRODUCTION}

Orofacial granulomatosis (OFG) is a rare, chronic granulomatous inflammatory disorder with relapsing orofacial swelling. The OFG patients could show lip or gingival enlargement, intraoral cobblestone appearance, lip fissure, and oral ulceration. Often OFG presents with facial nerve palsy ${ }^{1}$. Although the pathogenesis of OFG was not fully un-

Received November 2, 2018, Revised January 18, 2019, Accepted for publication January 23, 2019

Corresponding author: Jong Soo Hong, Department of Dermatology, Dongguk University Ilsan Hospital, Dongguk University College of Medicine, 27 Dongguk-ro, Ilsandong-gu, Goyang 10326, Korea. Tel: 82-31-961-7240, Fax: 82-31-961-7258, E-mail: jsttjstt@hanmail.net ORCID: https://orcid.org/0000-0003-3813-3055

This is an Open Access article distributed under the terms of the Creative Commons Attribution Non-Commercial License (http://creativecommons. org/licenses/by-nc/4.0) which permits unrestricted non-commercial use, distribution, and reproduction in any medium, provided the original work is properly cited.

Copyright $₫$ The Korean Dermatological Association and The Korean Society for Investigative Dermatology derstood, there are a few reports of association with tumors ${ }^{2}$. We report a case of synchronous OFG with brain cavernous hemangioma.

\section{CASE REPORT}

A 44-year-old female visited our dermatology clinic with repeated labial and perilabial swelling for months (Fig. 1A, B). Her symptoms were confined to the skin, and there were no symptoms such as facial palsy or fissured tongue. The physical examination revealed erythematous induration and swelling on the right lower lip and perioral area. She had been diagnosed with herpes simplex infection and received several antiviral treatments, but there was no improvement in symptoms.

Two weeks ago, because of both temporal headaches, she underwent the brain computed tomography scans and magnetic resonance imaging exam. Radiologically a mass was found on the petrosal apex and involving left clivus (Fig. 2A). The brain tumor and skin lesions were contralateral. The transsphenoidal tumor removal was performed for the brain tumor. During tumor section, the pulsating vessel was found. Considering the high probability of complication, tumor removal could not be completed. Finally, he was diagnosed as cavernous hemangioma. There was no postoperative complication such as neurologic symptoms, but her cutaneous symptoms seemed worse after the surgery.

We prescribed oral methylprednisolone $8 \mathrm{mg} /$ day and injected intralesional corticosteroid intermittently. Oral methylprednisolone was adjusted and tapered according to her symptoms but could not be completely withheld. Histologic examination revealed exocytosis of some lymphocytes and dense perivascular, perifollicular lymph histiocytic infiltration throughout the dermis (Fig. 3). Despite treat- 

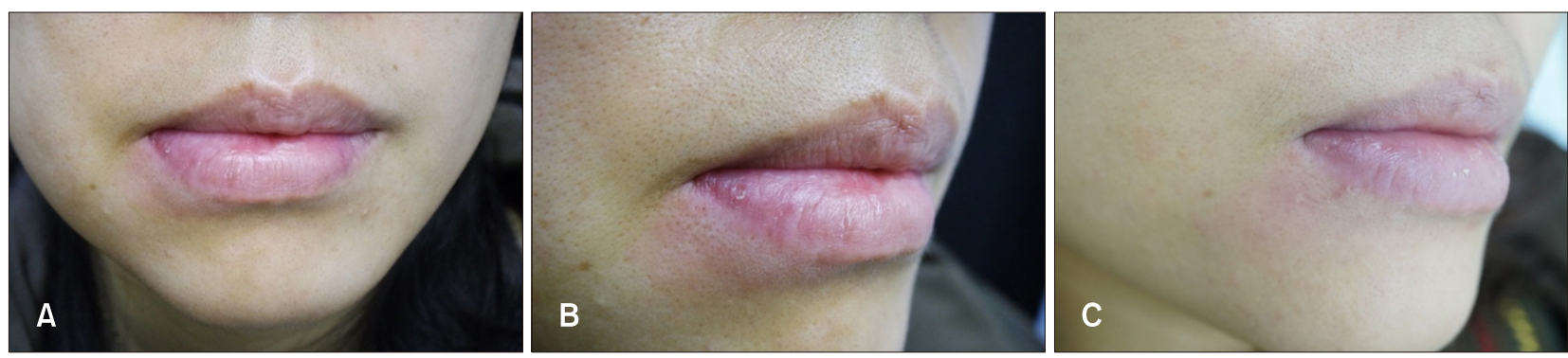

Fig. 1. (A, B) Erythema and swelling on the right lower lip and perioral area before treatment. (C) Improvement after stereotactic radiosurgery.
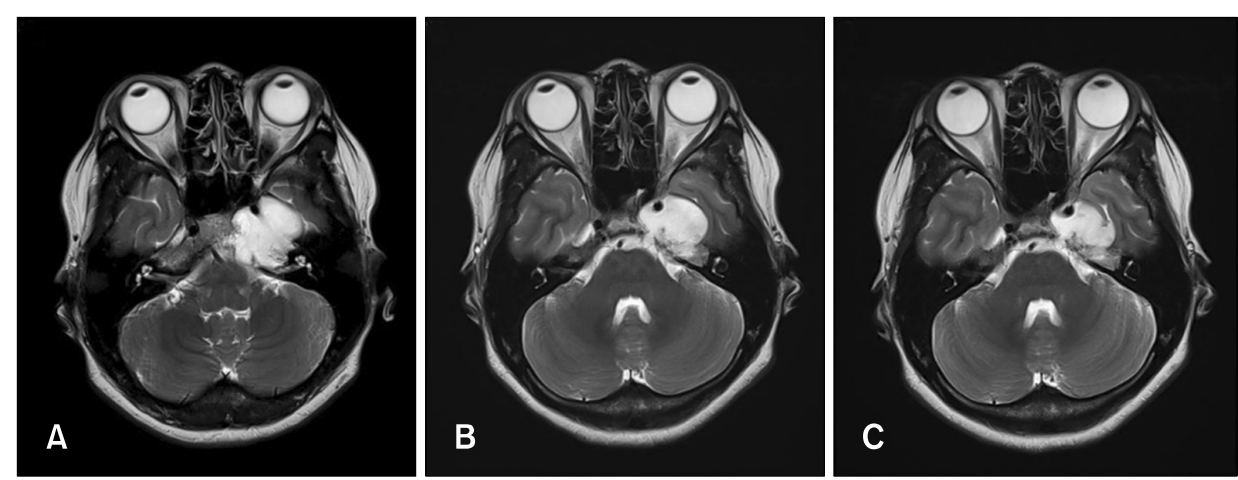

Fig. 2. (A) Large expansile lobulated mass involving left clivus, petrous bone, left cavernous sinus. (B, C) Serial decrease in tumor size after stereotactic radiosurgery. (A C) T2-weighted magnetic resonance images.
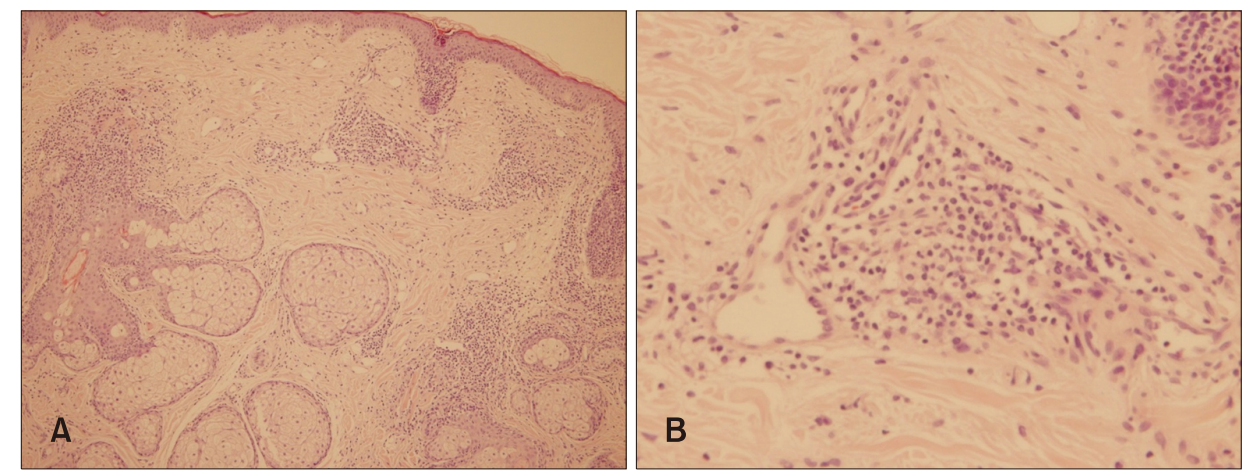

Fig. 3. (A, B) Dense perivascular and perifollicular lymphohistiocytic infiltration (H\&E: original magnifications $A, \times 100 ; B, \times 400)$.

ment with triamcinolone intralesional injection and oral methylprednisolone for 3 months, symptoms got worse. Oral doxycycline $200 \mathrm{mg}$ /day for 3months was ineffective also.

Seven months after the first visit, she was referred to a tertiary referral hospital for gamma knife surgery (GKS) on the brain tumor. After the GKS, although we prescribed the same dose of methylprednisolone as before, symptoms improved and showed less relapsing. Two months after GKS, oral methylprednisolone was discontinued and an intralesional injection was performed solely. Radiologically, brain mass was reduced in size (Fig. 2B, C), and her symptoms are improving consistently (Fig. 1C). We received the patient's consent form about publishing all photographic materials.

\section{DISCUSSION}

Melkersson-Rosenthal syndrome (MRS) is characterized by the triad of recurring facial nerve paralysis, lip swelling, and tongue fissure. With similar clinical entities, Wiesenfeld et al. $^{3}$ were the first to suggest the concept of OFG. OFG is defined a chronic granulomatosis disease affecting orofacial mucosa with characteristic histologic features that includes lymphohistiocytic infiltration, edema, and noncaseating granuloma. OFG is regarded as an umbrella term for including typical MRS, mono or oligosymptomatic presentation of $\mathrm{MRS}^{4}$. 
Also, OFG tends to overlap with clinical manifestations in Crohn disease, rosacea, sarcoidosis, and other systemic granulomatosis. Miest et al. ${ }^{5}$ reported only $41 \%$ of the patient with orofacial swelling and granulomatous inflammation was diagnosed as idiopathic OFG. The others were secondary OFG due to rosacea/acne vulgaris (12\%), Crohn disease $(10 \%)$, and contact dermatitis $(8 \%)^{5}$.

Treatment of mild OFG is topical corticosteroid or tacrolimus. In the case of moderate to severe OFG, systemic or intralesional corticosteroids are used. In the refractory case, immunomodulators including azathioprine and mycophenolate or thalidomide may be helpful ${ }^{1}$. Histopathologic features are helpful to the diagnosis of OFG, but not indispensable. McCartan et al. ${ }^{6}$ reported non-caseating granuloma was shown only $68 \%$ of OFG. Non-specific inflammatory infiltration could be seen without granulomatous inflammation ${ }^{6}$.

Etiology of OFG is unclear, but genetic predisposition, hypersensitivity to food, microbiologic factors are suggested ${ }^{7}$. On the other hand, de Souza Azevedo et al. ${ }^{2}$ reported a case of synchronous OFG and mucoepidermoid carcinoma. They speculated paraneoplastic syndrome could not be ruled out ${ }^{2}$. Paraneoplastic syndrome is the disorder accompanying begin or malignant tumors but occurs without direct invasion or metastasis of the primary tumor. Crurth's criteria are useful for the diagnosis of cutaneous paraneoplastic syndromes. The criteria include concurrent onset, parallel course, uniform neoplasm, statistical, and genetic association. Only the former two criteria are met, paraneoplastic syndrome can be considered ${ }^{8}$.

In our case, the improvement of OFG after stereotactic radiosurgery could be coincidental. Although reported cases of OFG associated with tumors are limited, the paraneoplastic syndrome cannot be excluded when considering Cruth's criteria. Also, stimulation of the tumor during incomplete resection might contribute to the deterioration of OFG. To the best of our knowledge, this case is the first report in the English literature of synchronous OFG with brain cavernous hemangioma.

\section{CONFLICTS OF INTEREST}

The authors have nothing to disclose.

\section{ORCID}

Seung Ju Yun, https://orcid.org/0000-0001-7743-0947

Ji Young Lee, https://orcid.org/0000-0002-7504-2761

Gwang Hoon Kim, https://orcid.org/0000-0001-8236-4622

Jong Heon Jeong, https://orcid.org/0000-0002-6489-1741

Ai-Young Lee, https://orcid.org/0000-0001-7720-7833

Seung Ho Lee, https://orcid.org/0000-0001-5057-1379

Jong Soo Hong, https://orcid.org/0000-0003-3813-3055

\section{REFERENCES}

1. Al Johani KA, Moles DR, Hodgson TA, Porter SR, Fedele S. Orofacial granulomatosis: clinical features and long-term outcome of therapy. J Am Acad Dermatol 2010;62:611620.

2. de Souza Azevedo R, Abrahão AC, de Albuquerque EB. Synchronous orofacial granulomatosis and mucoepidermoid carcinoma: paraneoplastic syndrome or coincidence? Oral Surg Oral Med Oral Pathol Oral Radiol Endod 2008; 106:e40-e45.

3. Wiesenfeld D, Ferguson MM, Mitchell DN, MacDonald DG, Scully C, Cochran K, et al. Oro-facial granulomatosis--a clinical and pathological analysis. Q J Med 1985;54:101-113.

4. Wehl G, Rauchenzauner M. A Systematic review of the literature of the three related disease entities cheilitis granulomatosa, orofacial granulomatosis and melkersson rosenthal syndrome. Curr Pediatr Rev 2018;14:196-203.

5. Miest RY, Bruce AJ, Comfere NI, Hadjicharalambous E, Endly $\mathrm{D}$, Lohse CM, et al. A diagnostic approach to recurrent orofacial swelling: a retrospective study of 104 patients. Mayo Clin Proc 2017;92:1053-1060.

6. McCartan BE, Healy CM, McCreary CE, Flint SR, Rogers S, Toner ME. Characteristics of patients with orofacial granulomatosis. Oral Dis 2011;17:696-704.

7. Miest R, Bruce A, Rogers RS 3rd. Orofacial granulomatosis. Clin Dermatol 2016;34:505-513.

8. Callen JP, Jorizzo JL, Bolognia JL, Zone JJ, Piette WW. Dermatological signs of internal disease. 4th ed. Philadelphia: Saunders/Elsevier, 2009. 452 p. 